\title{
EVI1 Mediated Stimulation of 3T3-L1 Preadipocyte Differentiation Is CtBP Dependent
}

\author{
M. J. Ireland, M. Al-Hasan, J. A. Craft, A. Graham, C. Bartholomew \\ Department of Life Sciences, School of Health \& Life Sciences, Glasgow Caledonian University, City Campus, Glasgow, Scotland \\ Email: c.bartholomew@gcu.ac.uk
}

How to cite this paper: Ireland, M.J., Al-Hasan, M., Craft, J.A., Graham, A. and Bartholomew, C. (2017) EVI1 Mediated Stimulation of 3T3-L1 Preadipocyte Differentiation Is CtBP Dependent. Yangtze Medicine, 1, 133-147.

https://doi.org/10.4236/ym.2017.13014

Received: June 5, 2017

Accepted: September 18, 2017

Published: September 21, 2017

Copyright $\odot 2017$ by authors and Scientific Research Publishing Inc. This work is licensed under the Creative Commons Attribution International License (CC BY 4.0).

http://creativecommons.org/licenses/by/4.0/

\begin{abstract}
Myelodysplasia syndrome $1(M D S 1)$ and Ecotropic viral integration site 1 (EVII) complex (MECOM) locus encode multiple isoforms of the EVI1 protein that are essential for normal vertebrate development and when inappropriately expressed play a significant role in malignancy and in particular leukaemias. However, the function of individual EVI1 isoforms is not fully understood. Recently, EVI1 or PRDM3, which is structurally closely related to the brown adipose tissue determining factor PRDM16, was shown to be required for differentiation of adipocytes. In this study, we show that 3T3-L1 preadipocytes sustain expression of all Evil isoforms examined, including Mds1-Evil, Evi1FL, Evi1 $\Delta 324$, Evi1FL +9 and Evi1 $\Delta 105$ throughout the adipogenesis differentiation programme. We also show that differentiation markers are enhanced by enforced expression of either Evil, EvilFL +9 or Evi1 $\Delta 105$ isoforms. Interestingly 3T3-L1 differentiation markers are also moderately enhanced by enforced expression of Evi1 $\Delta 324$, which lacks part of the N-terminal zinc finger domain (ZF1), demonstrating a biological activity for this particular isoform. Enforced expression of an Evil mutant lacking C-terminal binding protein (CtBP) co-repressor protein binding activity fails to stimulate 3T3-L1 differentiation markers and may have dominant negative activity, causing partial inhibition of this developmental programme. These studies show that multiple EVI1 isoforms are expressed in adipocytes and can stimulate adipogenic markers in a manner that is partially independent of the ZF1 DNA binding domain but fully dependent upon interaction with co-repressor CtBP proteins.
\end{abstract}

\section{Keywords}

MECOM, PRDM3, EVI1 Isoforms, C-Terminal Binding Proteins, Adipogenesis 


\section{Introduction}

Myelodysplasia syndrome 1 (MDS1) and Ecotropic virus integration site 1 (EVI1) complex (MECOM) locus gene transcripts include MDS1, EVI1 and a fusion of part of $M D S 1$ with $E V I 1$ [1] and their inappropriate expressions are associated with poor prognosis leukaemias and other malignancies [2] [3]. Those transcripts containing $E V I 1$ encode transcription factors with multiple cys 2 his 2 zinc finger DNA binding motifs [4] and are required for mammalian development [5]. EVI1 has been shown to contribute to a number of developmental programmes including maintenance of haemopoietic stem cells and various committed progenitor cells in haemopoiesis [6], neuroectodermal cell differentiation [7], nephrogenesis [8] and cardiac development [9].

EVI1 is also known as positive regulatory domain I-binding factor 1, retinoblastoma protein-binding zinc finger protein (PR) domain protein 3 (PRDM3) and the structurally similar PRDM16 is a key regulator of brown adipose tissue development [10]. Recent studies show that EVI1 also participates in adipogenesis [11] [12]. These studies show that EVI1 converts nonadipogenic cells to adipocytes and knockdown (KD) suppresses preadipocyte differentiation by impairing CCAAT/Enhancer-binding protein-beta (CEBP $\beta)$ assisted induction of peroxisome proliferator-activated receptor-gamma $2\left(\operatorname{PPAR} \gamma_{2}\right)$.

There are multiple naturally occurring isoforms of EVI1 but it is not known which are expressed in preadipocytes and which might participate in adipogenesis as all are potentially affected in the knockdown (KD) study of Ishibashi et al., 2012. The isoforms include MDS1-EVI1, EVI1FL, EVI1 324 [13], EVI1RP+ and EVI1 105 (murine specific) [14]. MDS1-EVI1 comprises intergenic transcripts containing coding exons of both the MDS1 and the EVIl genes and encodes an EVI1 protein with an N-terminal PR domain. EVI1FL is the original full length murine protein encoded by the cDNA first isolated from leukaemia cells [4]. EVI1RP+ is similar to EVI1FL but has an additional 9 amino acids inserted within the repressor domain (RP). EVI1 $\Delta 324$ lacks 324 amino acids, including part of the first zinc finger domain up to, but excluding, RP and EVI1 $\Delta 105$ has 105 C-terminal amino acids deleted. Various properties have been attributed to some of these isoforms and in some instances they have been shown to have opposing activities. For example, MDS1-EVI1 has been associated with tumor suppressing activity whereas EVI1FL is oncogenic. MDS1-EVI1 activates AGATA motif promoters whereas EVI1FL represses [1], EVI1FL inhibits 32Dcl3 cell response to granulocyte-colony stimulating factor (G-CSF) and transforming growth factor beta $\left(\mathrm{TGF} \beta_{1}\right)$ whereas MDS1-EVI1 has no effect on G-CSF response and enhances TGF $\beta_{1}$ signalling [15] and EVI1FL enhances proliferation of haemopoietic colonies from differentiating embryonal stem (ES) cells whereas MDS1-EVI1 represses these activities [16]. The MDS1-EVI1 isoform has a PR domain [17] which confers intrinsic histone $\mathrm{H} 3$ lysine 9 monomethyltransferase catalytic activity [18] which is absent from other EVI1 isoforms.

The significance of the remaining isoforms remains unclear. Studies show ex- 
pression of each isoform in all tissues examined but little difference in DNA binding, CtBP protein binding, transcriptional repression or cell transformation activities between EVI1FL, EVI1RP+ or EVI1 $\Delta 105$ [14]. EVI1 $\Delta 324$ however lacks $3 \mathrm{~N}$-terminal zinc fingers (ZF1), neither binds nor represses transcription via ZF1 DNA binding sites, does not transform fibroblasts [19] and to date no biological activity has been assigned to this isoform.

In this study we investigate the profile of expression and biological activity of EVI1 isoforms in 3T3-L1 preadipocytes and throughout the adipocyte differentiation programme.

\section{Materials and Methods}

\subsection{Cell Culture}

Plat-E (Cambridge Bioscience, Cambridge, UK, RV-101) and 3T3-L1 (ATCC ${ }^{\circledR}$ CL-173 ${ }^{\mathrm{TM}}$ ) cells were cultured in complete medium (CM) comprising Dulbecco's Modified Eagle's Medium (Lonza Group Ltd., Basel, Switzerland, BE12-604F) supplemented with $10 \%(\mathrm{v} / \mathrm{v})$ newborn calf serum (3T3-L1) (Sigma-Aldrich, Poole, UK, N4637) or 10\% (v/v) foetal calf serum (Plat-E cells) (FCS, Lonza, DE14-801F) and $2.5 \mathrm{mM}$ glutamine, $50 \mu \mathrm{g} / \mathrm{ml}$ penicillin, 50 units/ml streptomycin (Lonza Group Ltd., BE17-605E and BE17-603E), $37^{\circ} \mathrm{C}, 5 \% \mathrm{CO}_{2}$. For differentiation 3T3-L1 were cultured with induction medium 1 (IM1), comprising CM with $10 \%$ (v/v) FCS, $5 \mu \mathrm{g} / \mathrm{ml}$ insulin (Sigma-Aldrich, I9278), $0.25 \mu \mathrm{M}$ dexamethasone (Sigma-Aldrich, D4902), $0.5 \mathrm{mM}$ Isobutylmethylxanthine (IBMX, Sigma-Aldrich I5879), for $48 \mathrm{~h}$ followed by a further $48 \mathrm{~h}$ incubation with induction medium 2 (IM2) comprising CM supplemented with $10 \%$ FCS and $5 \mu \mathrm{g} / \mathrm{ml}$ insulin. Culture medium was subsequently replaced with fresh IM2 every $48 \mathrm{~h}$ for up to 10 days. For retrovirus production, Plat-E cells were transiently transfected with retroviral plasmid DNA using Fugene6 ${ }^{\circledR}$ (Roche Diagnostics GmbH, Mannheim, Germany, 11815091001); virus was harvested and used to infect 3T3-L1 as described before [20].

\subsection{Preparation of Total Cellular RNA, cDNA Synthesis and Quantitative Real-Time Polymerase Chain Reaction QPCR}

RNA was prepared from cultures of cells by the TRI Reagent ${ }^{\circledR}$ method (Sigma-Aldrich, 93289). Total cellular RNA (1 $\mu \mathrm{g})$ was used to synthesise cDNA using Maxima reverse transcriptase (Thermo Fisher Scientific Inc., St. Leon-Rot, Germany, EP0742) with random hexamer (Thermo Fisher Scientific, S0142) and oligo dT (Thermo Fisher Scientific, S0131) primers according to the manufacturer's instructions. The cDNA reaction (5\%) was used for real time quantitative polymerase chain reaction using QPCR SYBR Green mix (Thermo Fisher Scientific, 11873913), gene specific oligonucleotide primers (Integrated DNA Technologies, Leuven, Belgium), $95^{\circ} \mathrm{C}$, 15 min followed by 40 cycles $95^{\circ} \mathrm{C}, 30 \mathrm{~s}, 60^{\circ} \mathrm{C}, 30 \mathrm{~s}$ in a CFX96 C1000 Thermal cycler (BIO-RAD Laboratories Ltd., Hemel Hempstead, UK).

The efficiency of the Q-PCR reactions were calculated by using the formula Efficiency $=-1+10^{(-1 / \text { slope })}$ against the standard curve of each assay over a gra- 
dient of template concentration with each gene. The efficiency of primers are Ca3 (88\%), Clebpa (75\%), Ppary 2 (92\%), Fabp4 (91\%), Evil (101\%) and Gapdh (90\%). Relative expression levels between target and Gapdh were determined using the arithmetic comparative $2^{-\Delta \Delta \mathrm{Ct}}$ method [21] and were determined relative to the target gene in MX infected 3T3-L1 cells (calibrator). Oligonucleotide primers were supplied by Integrated DNA Technologies (Leuven, Belgium) $P \operatorname{par}_{2}$ FP: GCCCACCAACTTCGGAATC, Ppar $\gamma_{2} R P$ : TGCGAGTGGTCTTCC ATCAC, C/ebpaFP: GAGCTGAGTGAGGCTCTCATTCT, C/ebpaRP: TGGGA GGCAGACGAAAAAAC, Fabp4FP: GGGCGTGGAATTCGATGAAATCA, Fab p4RP: CCCGCCATCTAGGGTTATGAT, Evil FP: CGCTTGAAGCTTTGAAAG AAAAATA, Evil RP: TGTTCTCAATTGCTGACATTTGC, Evil probe (HEX): TTGAGACCTTCTCCAGGATTCTTGTTTCACC, Ca3FP: CCGGGACTATTGG ACCTATCAC, Ca3RP. TTGAGCAGCAGCCACACAA, Ca3 probe (FAM): CTCC TTCACCACGCCGCCCTG, GapdhFP: GGGCTGCCCAGAACATCA, GapdhRP. CCGTTCAGCTCTGGGATGAC, Gapdh probe (FAM): CCCTGCATCCACTG GTGCTGCC.

\subsection{Endpoint PCR}

cDNA $(0.5 \mu \mathrm{l})$ was amplified by PCR with $140 \mathrm{ng} / \mu \mathrm{l}$ forward and reverse primers using ReddyMix PCR master mix [1.5 $\mathrm{mM} \mathrm{MgCl}_{2}$ ] (Thermoscientific) $95^{\circ} \mathrm{C}, 5$ min followed by 40 cycles $95^{\circ} \mathrm{C}, 15 \mathrm{~s}, 60^{\circ} \mathrm{C}, 60 \mathrm{~s}$ in a PTC-100 (MJ Research, Inc.). Products were analysed by $3 \%(w / v)$ agarose gel electrophoresis in $40 \mathrm{mM}$ Tris-acetate, $1 \mathrm{mM}$ EDTA (pH 8.0) buffer (1XTAE). Oligonucleotide primers were supplied by Integrated DNA Technologies. Mds1/Evil and Evil specific primers were $E F, M F 1$ and $G S P 3$ [22], RP+ primers were $M E 1 / M E 3$ and $\triangle 105$ primers were $M E 2 / M E 4$ [14] and $\triangle 324$ primers were $\triangle 324 F$. CGTCA GGGCCTCAAACAGC, $\triangle 324 R$ : GGGTACATTGATTGAGAGAATGAGA. CtBP 1 and 2 primers were: $C t B P 1 F P$, CACACAGGAGATCCATGAGAAG, $C t B P 1 R P$, CTCTGGTCAGTGTGATGGTATG, $C t B P 2 F P$, GCACAGTCCACTCAGGAAAT, $C t B P 2 R P$; CCTTGAACTTCTCCAGGTCTTC.

\subsection{Western Blot Analysis}

Protein extracts, SDS polyacrylamide gel electrophoresis and western blotting were performed as described previously [23] with either $\alpha$-EVI1 (1806) or $\alpha$-GAPDH (Fitzgerald Industries, North Acton, MA, USA, 6C5) diluted 1/1000 (1806) or $1 / 5000$ (6C5) respectively. Appropriate IRDye ${ }^{\circledR} 800 \mathrm{CW}$ conjugated anti-rabbit (Li-Cor Biosciences, 926-32211) or IRDye ${ }^{\circledR} 680 \mathrm{RD}$ conjugated anti-mouse (Li-Cor Biosciences, 926-68072) IgG secondary antibodies were used at 1/15000 dilutions and detection was performed by fluorescence using an Odyssey Fc Imaging System (Li-Cor Biosciences).

\subsection{Statistical Analysis}

Unpaired Student's t-test was used to determine the significance of data using 
Graphpad Prism ${ }^{\circledast} 6.0$ software. $\mathrm{P} \leq 0.05$ was considered significant. ${ }^{\star} \mathrm{P} \leq 0.05$,

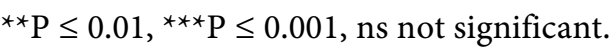

\section{Results}

\subsection{Enforced Expression of EVI1 in 3T3-L1 Preadipocytes}

In order to investigate the effect of EVI1 expression on adipogenesis it was expressed in 3T3-L1 cells. Initially Plat-E cells were transiently transfected with the previously described Evi1FL encoding p50M5.6-neo retroviral vector [20] and the resulting virus containing supernatants used to infect varying numbers of 3T3-L1 cells (Materials and Methods). The 3T3-L1 cells were re-infected with virus containing supernatant again $24 \mathrm{hrs}$ later. After virus infection $(48 \mathrm{~h})$ cells were examined for Evil expression by western blot analysis with $\alpha$-EVI1. The results show production of the $145 \mathrm{kd}$ Evil protein in cells infected with the 5.6 retroviral vector (Figure 1(a)). Even loading of samples was confirmed by western blot analysis with $\alpha$-GAPDH (Figure 1(a)). Highest Evil expression is observed when either $2 \times 10^{4}$ or $5 \times 10^{4}$ cells were used for virus infection and therefore 5 $\times 10^{4}$ cells were chosen for further experiments.

\subsection{EVI1 Enhances 3T3-L1 Adipocyte Differentiation}

To investigate the impact of enforced EVI1FL expression on adipogenesis it was expressed in 3T3-L1 cells using the transient retroviral infection scheme and subsequent induction of adipocyte differentiation programme outlined in Figure 1(b). Cells were transiently infected with either p50MX-neo (MX, empty vector control) or p50M5.6-neo (5.6) virus, induced to differentiate and RNA prepared from cell extracts at various time points. Initially, expression of the adipocyte differentiation marker gene Fabp4 at days 0 and 10 were examined. The results show induction of this marker for both control infected cells as well as cells with enforced expression of Evil (Figure 1(c), MX, 5.6), however the induction of Fabp4 is significantly increased in cells with enforced Evil expression at day 10 compared to MX infected cells on the same day (Figure 1(c), 5.6).

We next examined expression of key regulators of adipocyte differentiation $P_{\text {Par }}$ and C/ebpa in the presence (5.6) or absence (MX) of Evil at days 0, 1, 2, 3 and 4 of induction. The results show that both markers are induced during the 4 day period but accumulate to significantly higher levels in the presence of Evil (Figure 2(a), Figure 2(b), 5.6) when compared with empty vector infected cells at each point examined (Figure 2(a), Figure 2(b), MX). Ppar $\gamma_{2}$ expression initially declines between day 0 and days 1 and 2 in MX and 5.6 cells but one-way ANOVA and Dunnett's multiple comparison post-test using MX day 0 or 5.6 day 0 as control group confirms significant increases by day $4[\mathrm{P} \leq 0.001$ (MX), $\mathrm{P} \leq 0.05$ (5.6)]. Other studies have shown that the enzyme carbonic anhydrase III (Ca3) is induced during adipocyte differentiation [24] and is either a marker or regulator of this process. Ca3 gene expression increases significantly (D1 $\mathrm{p} \leq$ $0.01, \mathrm{D} 2, \mathrm{D} 3$ and D4, P $\leq$ 0.001) in control MX cells compared to levels at D0 in- 
(a)

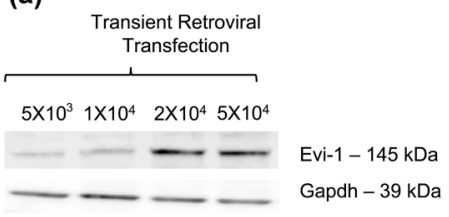

(b)

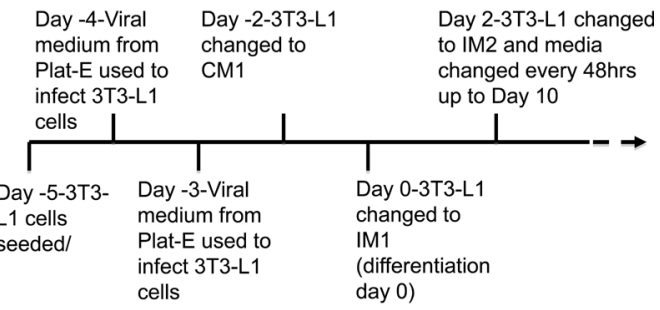

(c)

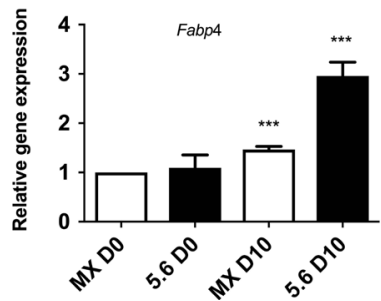

Figure 1. (a) Western blot analysis of whole cell protein extracts derived from 3T3-L1 cells transiently infected with p50M5.6neo retrovirus. The number of cells exposed to retrovirus is shown at the top of each lane. The size of Evi-1 and Gapdh proteins observed with $\alpha$-Evil and $\alpha$-Gapdh are indicated; (b) Strategy for transient retroviral infection of 3T3-L1 cells and timeline for induction of differentiation. Complete media (CM1), induction media 1 (IM1) and 2 (IM2) are described in materials \& methods; (c) Histogram showing relative gene expression of Fabp4 in empty vector control (MX, clear bars) and Evil vector (5.6, black bars) infected 3T3-L1 cells at days 0 (D0) and 10 (D10) of differentiation. Error bars are the standard deviation of $3(n=3)$ independent virus infection and differentiation experiments. ${ }^{* *} \mathrm{P} \leq 0.001$ indicates statistical significance of MXD10 vs. MXD0 and 5.6D10 vs. MXD10.

(a)

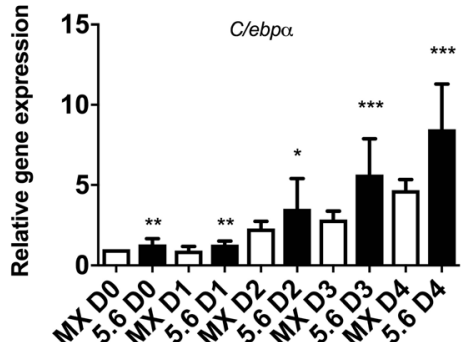

(c)

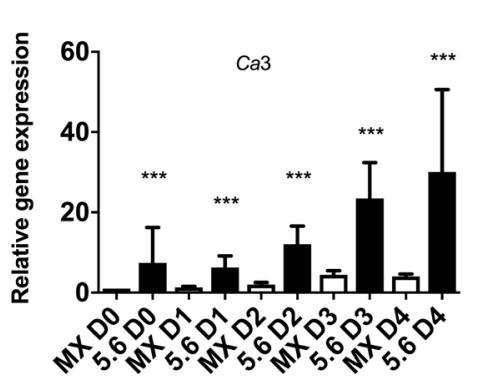

(b)

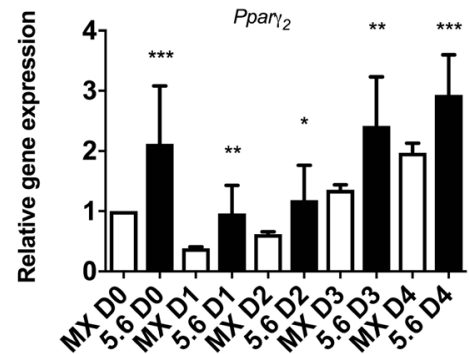

(d)

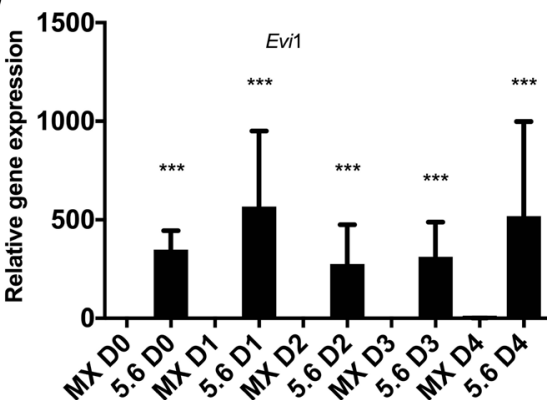

Figure 2. Histograms showing relative gene expression of C/ebpa (a), Ppary (b), Ca3 (c) and Evil (d) in empty vector control (MX, white bars) and Evil vector (5.6, black bars) virus infected 3T3-L1 cells at days 0 (D0), 1 (D1), 2 (D2), 3 (D3) and 4 (D4) of differentiation. Error bars are the standard deviation of $3(n=3)$ independent virus infection and differentiation experiments. ${ }^{*} \mathrm{P} \leq 0.05,{ }^{* *} \mathrm{P} \leq 0.01,{ }^{* * *} \mathrm{P} \leq 0.001$ indicates statistically significant differences in expression of the indicated gene for EVI1 expressing cells (5.6) compared to MX infected cells on the same day. 
dicating progression through the differentiation programme. Comparison of Ca3 gene expression in MX and 5.6 cells shows its expression is significantly elevated in 3T3-L1 cells with enforced expression of Evi-1 (Figure 2(c), 5.6) compared with cells examined at the same time point that were infected with the empty vector (Figure 2(c), MX). Finally, Evil transgene expression was maintained for at least the 4 day duration of the transient expression and differentiation system as its mRNA expression is significantly higher in 5.6 infected cells compared with low, but detectable, endogenous Evil expression observed in MX infected 3T3-L1 cells at each time point examined (Figure 2(d), MX, 5.6).

\subsection{Naturally Occurring EVI1 Splice Variants, RP+, $\Delta 105$ and $\Delta 324$ Stimulate 3T3-L1 Adipocyte Differentiation}

These data suggest enforced expression of Evil accelerates adipocyte differentiation of induced 3T3-L1 cells. Multiple, naturally occurring Evil splice variants exist in murine cells [14]. A schematic representation of the isoform shown to stimulate adipocyte differentiation (Figure 2) is shown in Figure 3, designated EVI1FL, along with other splice variants MDS1/EVI1, EVI1RP+ (RP+), EVI1 $\Delta 324$ $(\Delta 324)$ and EVI1 $\Delta 105(\Delta 105)$. Endogenous expression of each of these in 3T3-L1 cells, in preadipocytes (Figure $4(\mathrm{a})$ ) and throughout 10 days of differentiation (data not shown), was confirmed using isoform specific oligonucleotide primers (Materials and Methods) by end point PCR.

Since all isoforms examined are expressed in 3T3-L1 cells we investigated which can induce adipocyte differentiation. Previously described retroviral vectors [14] [19] were used to transiently express each isoform (RP+, $\Delta 324$ and $\Delta 105)$ in 3T3-L1 cells. Infected cells were induced to differentiate and similar levels of

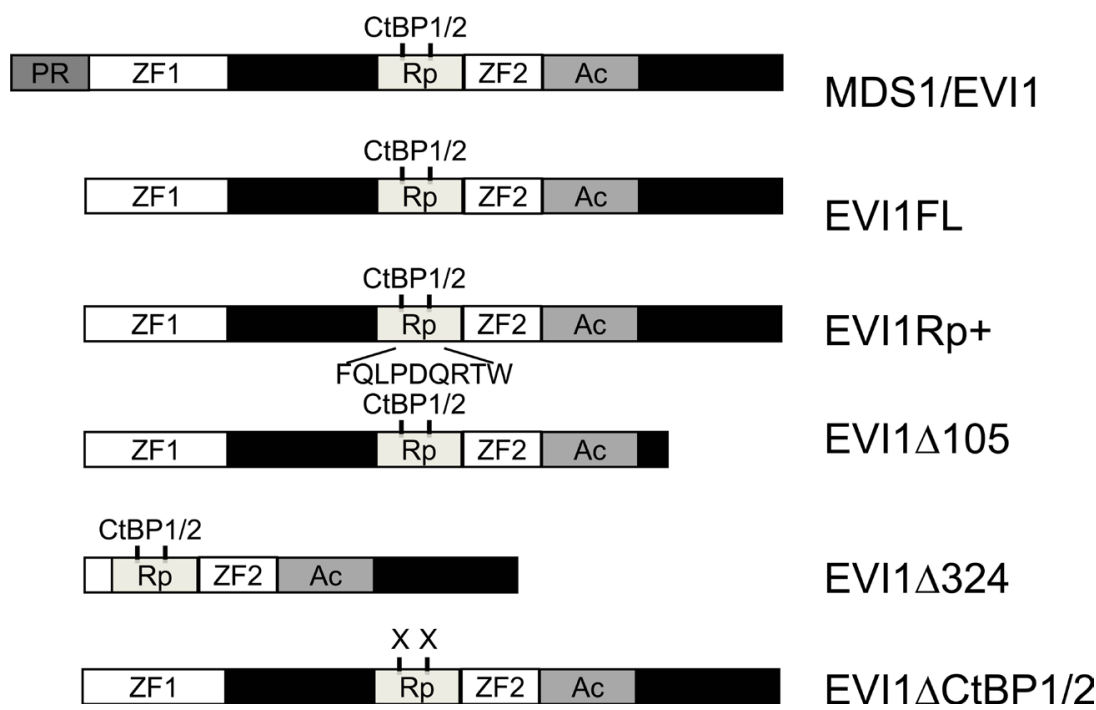

Figure 3. Schematic representation of the domain structure of the indicated EVI1 splice variant encoded proteins showing the $\mathrm{PR}$ domain $(\mathrm{PR}), 1^{\text {st }}$ and second $2^{\text {nd }}$ zinc finger domains (ZF1 \& ZF2), repressor domain (Rp), acidic domain (Ac), CtBP binding sites 1 $\& 2$ and the additional 9 amino acids (single letter amino acid code) found in the repressor domain of $\mathrm{Rp}+$. X indicates $\mathrm{CtBP}$ binding inactivating point mutations. 
(a)

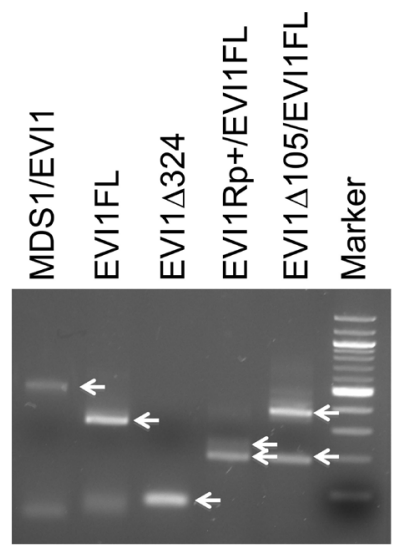

(b)

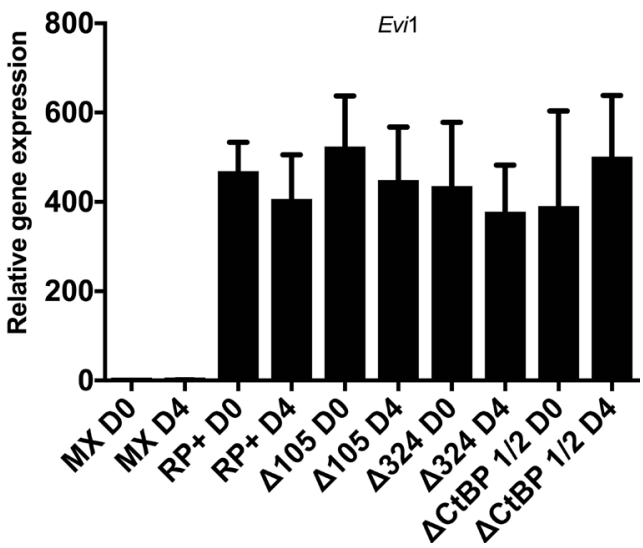

Figure 4. (a) Agarose gel (3\% NuSieve ${ }^{\circledR}$ 3-1 agarose, Lonza) electrophoresis of end point PCR products for EVI1 splice variants at day 0 of 3T3-L1 cell differentiation. White arrows indicate amplified DNA fragments of the expected size for each splice variant: MSD1/EVI1 460 bp; EVI1FL 298 bp; EVI1 32476 bp; EVI1RP+/EVI1FL 216 bp/189bp; EVI1 $\Delta$ 105/EVI1FL 187 bp/371bp. Marker is 100 bp ladder (quickload, New England Biolabs); (b) Histogram showing relative gene expression of Evil in empty vector control (MX, white bars) and indicated Evil splice variant vector infected 3T3-L1 cells at days 0 (D0) and 4 (D4) of differentiation. Error bars are the standard deviation of $3(n=3)$ independent virus infection and differentiation experiments. There is no statistically significant difference in expression of each mutant form relative to EVI1RP+ $(\mathrm{RP}+)$ at day 0.

ectopic expression of Evil splice variants was achieved over the 4 days examined (Figure 4(b)).

Cells were then examined for expression of Fabp4, Ca3 (day 0 and 10), Ppar $\gamma_{2}$ and $C / e b p a$ (day 0, 1, 2, 3 and 4). In each case gene expression in Evil isoform expressing cells was compared to MX infected cells on the same day. Surprisingly, the results show a significant increase in induction of Fabp4 (Figure 5(a)) and Ca3 (Figure 5(b)) expression in induced 3T3-L1 cells at day 10 with each isoform examined. Furthermore, both $\mathrm{RP}+$ or $\Delta 105$ isoform expression results in a significant increase in C/ebpa and $P_{\text {par }}$ (Figure 6(a), Figure 6(b), RP+ D3 and 4, $\Delta 105 \mathrm{D} 3$ and 4 vs. MXD3 and 4) gene expression. $\Delta 324$ transgene expression results in a significant increase in both $C / e b p \alpha$ and Ppar $\gamma_{2}$ gene expression at day 3 (Figure 6(a), Figure 6(b), $\Delta 324 \mathrm{D} 3$ vs. MXD3) but no significant change at day 4 (Figure 6(a), Figure 6(b), $\Delta 324 \mathrm{D} 4$ vs. MXD4).

\subsection{Interaction with CtBP Proteins Is Required for EVI1 Mediated Stimulation of 3T3-L1 Adipogenesis}

The results suggest that enforced expression of each naturally occurring Evil isoform tested can stimulate adipogenesis in induced 3T3-L1 cells. Evi1 interacts with CtBP proteins to mediate some biological activities and so we investigated if this interaction is required to stimulate adipocyte differentiation markers as well. A retroviral vector encoding a CtBP binding mutant EVI1 $\Delta \mathrm{CtBP} 1 / 2(\Delta \mathrm{CtBP} 1 / 2)$ 
(a)

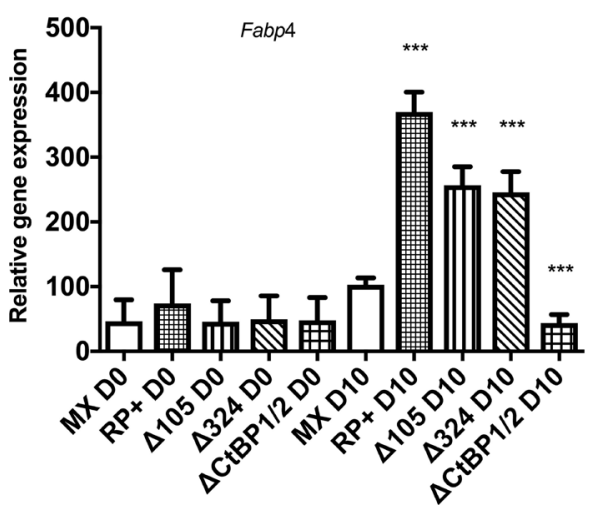

(b)

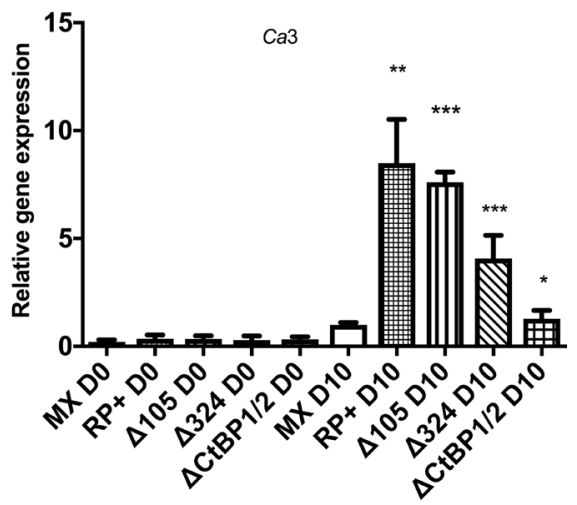

Figure 5. Histograms showing relative gene expression of Fabp4 (a) and Ca3 (b) in empty vector control $(\mathrm{MX})$ and EVI1RP+ $(\mathrm{RP}+), \operatorname{EVI} 1 \Delta 105(\Delta 105), \operatorname{EVI} 1 \Delta 324(\Delta 324)$ and EVI1 $\Delta \mathrm{CtBP} 1 / 2(\Delta \mathrm{CtBP} 1 / 2)$ virus infected 3T3-L1 cells at days $0(\mathrm{D} 0)$ and 10 (D10) of differentiation. Error bars are the standard deviation of $3(n=3)$ independent virus infection and differentiation experiments. ${ }^{\star} \mathrm{P} \leq 0.05,{ }^{* *} \mathrm{P} \leq 0.01,{ }^{* *} \mathrm{P} \leq 0.001$ indicates statistically significant differences in expression of the indicated gene for each form of EVI1 relative to MX infected cells at day 10 .

(Figure 3) that is unable to bind CtBP proteins [25] was transiently expressed in 3T3-L1 cells. The cells were induced to differentiate and examined for expression of the same molecular markers as before. $\triangle \mathrm{CtBP} 1 / 2$ mutant transgene expression was observed at similar levels to the other Evil isoforms studied (Figure 4 (b), $\triangle \mathrm{CtBP} 1 / 2 \mathrm{D} 0$ and $\mathrm{D} 4)$. The results show that instead of an increase, there is a significant decrease in Fabp4 (Figure 5(a), Figure 5(b), $\Delta \mathrm{CtBP} 1 / 2 \mathrm{D} 10$ ), C/ebpa and Ppar $\gamma_{2}$ (Figure 6(a), Figure 6(b), $\triangle \mathrm{CtBP} 1 / 2$ D4) gene expression in $\triangle \mathrm{CtBP} 1 / 2$ expressing cells when compared to cells infected with the empty vector (MX) control on the same days. Only Ca3 gene expression shows a small increase in expression in cells with enforced $\triangle \mathrm{CtBP} 1 / 2$ expression (Figure 5(b), $\triangle \mathrm{CtBP} 1 / 2 \mathrm{D} 10)$. Expression of both $C t B P 1$ and $C t B P 2$ genes are observed throughout the 3T3-L1 cell differentiation programme (Figure 6(c)). These data show that Evi1 mediated stimulation of 3T3-L1 cell differentiation markers is dependent on interaction with CtBP binding proteins.

\section{Discussion}

In this study a transient retroviral infection system was developed to investigate the effect of enforced EVI1 expression on 3T3-L1 pre-adipocyte cell differentiation to adipocytes. Results show that under these conditions EVI1 enhances chemically induced 3T3-L1 differentiation as measured by characteristic gene markers and mediators of this process (Fabp4,Ca3,C/ebpa and Ppar $\gamma_{2}$ ). Furthermore, we show that all previously described and naturally occurring EVI1 splice variants are expressed in 3T3-L1 preadipocytes as well as throughout the differentiation programme and that enforced expression of splice variants EVI1RP+, EVI1 $\Delta 105$ and EVI1 $\Delta 324$ similarly enhance the process. Finally, we demonstrate 
(a)

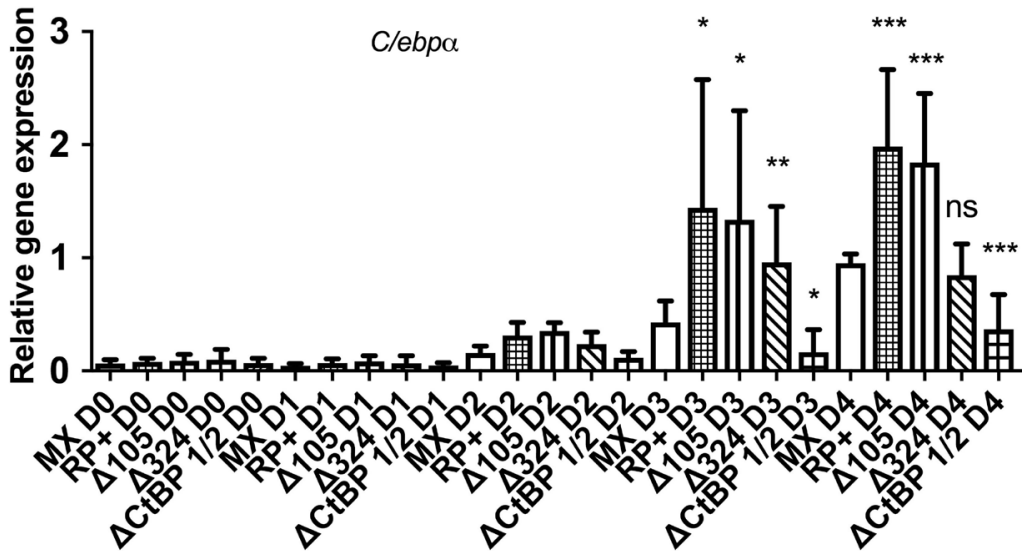

(b)

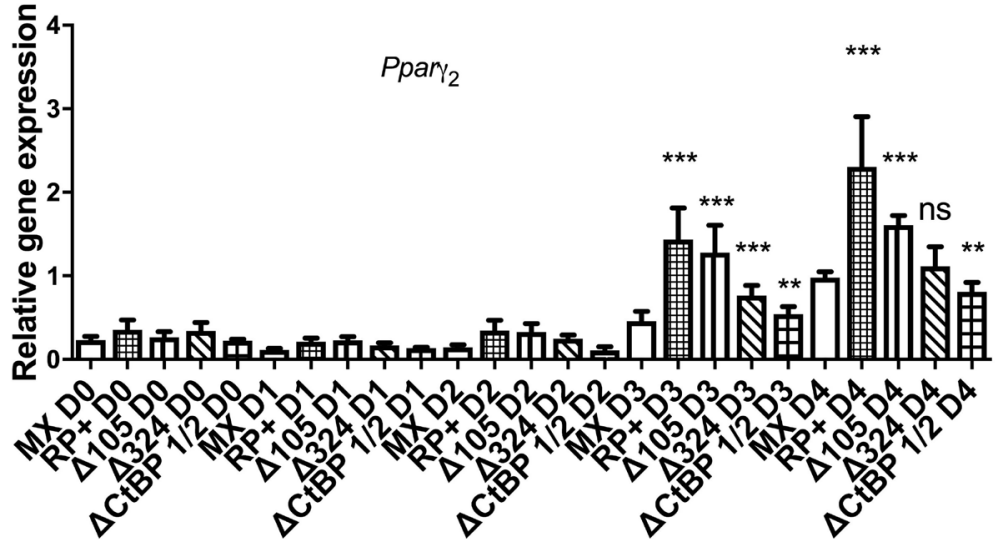

(c)

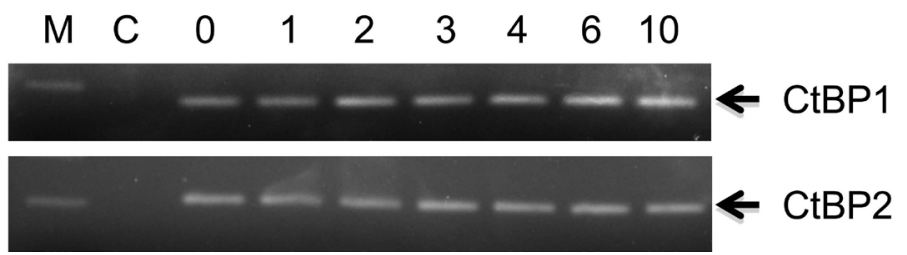

Figure 6. Histograms showing relative gene expression of C/ebpa (a) and $\operatorname{Ppar}_{2}$ (b), in empty vector control (MX) and EVI1Rp+9 (Rp+), EVI1 $\Delta 105(\Delta 105)$, EVI1 $\Delta 324(\Delta 324)$ and EVI1 $\Delta \mathrm{CtBP} 1 / 2(\Delta \mathrm{CtBP} 1 / 2)$ virus infected 3T3-L1 cells at days $0(\mathrm{D} 0), 1$ (D1), 2 (D2), 3 (D3) and 4 (D4) of differentiation. Error bars are the standard deviation of $3(n=3)$ independent virus infection and differentiation experiments. Statistical analysis of days 3 (D3) and 4 (D4) data only are shown. ${ }^{* * P} \leq 0.01,{ }^{* *} \mathrm{P} \leq 0.001$ indicates statistically significant differences in expression of the indicated gene for each form of EVI1 relative to MX infected cells on the same day. ns indicates no significant difference in expression relative to MX infected cells on the same day. (c) Agarose gel (3\% NuSieve 3-1 agarose) electrophoresis of end point PCR products for $C t B P 1$ and $C t B P 2$ gene expression at indicated days $0,1,2,3,4,6$ and 10 of 3T3-L1 cell differentiation. M indicates 100 bp ladder marker (quickload) and $\mathrm{C}$ the negative control.

that a mutant of EVI1, which no longer binds CtBP proteins, is unable to stimulate the 3T3-L1 differentiation markers that are observed with wild type variants. 
The efficiency of differentiation of empty vector control 3T3-L1 cells is suboptimal as indicated by relatively small changes in molecular marker gene expression shown in Figure 1(c); Figures 2(a)-(c); Figure 5(a) \& Figure 5(b) and Figure 6(a) \& Figure 6(b). In the virus infection and differentiation scheme used here (Figure 1(b)) 3T3-L1 cells are unlikely to be confluent for $48 \mathrm{hrs}$ prior to induction of differentiation as is normally the case [26] because of the need to optimize retroviral infection in dividing cells [27]. However, our results clearly show that differentiation is significantly enhanced by enforced expression of EVI1 under these conditions, based on the molecular markers examined. Following growth arrest, efficient induction of 3T3-L1 cell differentiation is accompanied by mitotic clonal expansion (MCE) [28]. Studies have shown that EVI1 stimulates cell proliferation [29] and this property may stimulate MCE, contributing to the enhanced expression of adipogenic markers observed here, which are consistent with previous observations [11].

All known naturally occurring EVI1 splice variants are expressed in preadipocytes and throughout differentiation of 3T3-L1 cells. The relative abundance of splice variants has not been determined in this study but others have shown that general EVI1 expression is low in proliferating preadipocytes, transiently peaks during chemical stimulation of differentiation then is low again for the remaining programme [11].

Enforced expression of splice variants EVI1FL, EVI1RP+, EVI1 $\Delta 105$ and EVI1 $\Delta 324$ are each capable of stimulating adipocyte differentiation based on relative increases in programme mediator (Cebp $\alpha$, Ppar $_{2}$ ) and marker (Fabp4, Ca3) gene expression (Figure 2, Figure 5, Figure 6). It is interesting that EVI1 $\Delta 324$ can stimulate adipogenic markers as this represents one of the few biological activities associated with the isoform to date. This splice variant lacks part of zinc finger 6 and all of zinc finger 7 of the ZF1 domain as well as 275 intervening amino acids to the Rp domain [30]. Recent studies show EVI1FL and EVI1 $\Delta 324$ co-regulate largely the same genes in cells and that EVI1 $\Delta 324$ can induce anchorage independent growth in HeLa cells [31]. However, our results show EVI1 $\Delta 324$ cannot fully complement the activity of the other EVI1 splice variants studied as stimulation of gene expression of the markers examined is less in most cases when compared with the other isoforms. This indicates the missing amino acids, including the ZF1 domain, are important for optimal EVI1 mediated stimulation of adipogenesis.

The interaction of EVI1 with CtBP proteins has previously been shown to be essential for biological activities including cell transformation [25] and inhibition of TGF $\beta$ signaling [32]. This study shows EVI1 mediated stimulation of adipogenic markers is also CtBP binding dependent. Interestingly, EVI1 $\Delta \mathrm{CtBP} 1 / 2$ not only fails to stimulate adipogenic markers in 3T3-L1 cells but it actually appears to repress them when compared with MX infected cells. Gene expression of Fabp4,C/ebpa and Ppar $\gamma_{2}$ are all significantly repressed in EVI1 $\triangle \mathrm{CtBP} 1 / 2$ expressing cells (Figure 5 and Figure 6 ) which suggests it has dominant negative 
activity with regard to adipocyte differentiation. Other regulators of adipogenesis are also dependent upon CtBP complexes including Klf3 [33], Fog1 and Fog2

[34]. Both CtBP1 and CtBP2 are expressed throughout adipocyte differentiation (Figure 6(c)) and their binding is required for both negative (Klf3, Fog1 and Fog2) and positive (EVI1) regulation. Furthermore, the EVI1 related protein PRDM16 also binds CtBP proteins to repress white fat specific genes and are displaced to promote brown adipose tissue development [35]. CtBP proteins bind NAD+ and $\mathrm{NADH}$ with higher affinity for the latter which promotes interaction with partner proteins [36]. CtBP proteins have been proposed to have a role in metabolic sensing [37]. High calorie intake is associated with increased levels of NADH. Based on our study this would be predicted to promote association of EVI1 and CtBP and stimulate adipogenesis.

Obesity, the expansion of adipose tissue depots, is one underlying cause of major health conditions worldwide including both type 2 diabetes mellitus and cardiovascular disease, but the mechanisms involved are not fully understood. Understanding the molecular mechanisms regulating adipogenesis might identify novel targets for therapeutic intervention. Regulation of the adipogenesis developmental programme is controlled by a complex network of transcription factors and EVI1 has only recently been identified to be involved in this process. These studies show for the first time that multiple EVI1 isoforms are expressed in adipocytes and can stimulate adipogenic markers in a manner that is partially independent of the ZF1 DNA binding domain but fully dependent upon interaction with co-repressor CtBP proteins. Blocking EVI1/CtBP interaction may be a target for drug development controlling obesity.

\section{Acknowledgements}

This work was fully funded by a Glasgow Caledonian University PhD studentship awarded to Mark Ireland.

\section{References}

[1] Soderholm, J., Kobayashi, H., Mathieu, C., Rowley, J.D. and Nucifora, G. (1997) The Leukemia-Associated Gene MDS1/EVI1 Is a New Type of GATA-Binding Transactivator. Leukemia, 11, 352-358. https://doi.org/10.1038/sj.leu.2400584

[2] Koos, B., et al. (2011) The Transcription Factor Evi-1 Is Overexpressed, Promotes Proliferation, and Is Prognostically Unfavorable in Infratentorial Ependymomas. Clin. Cancer Research, 17, 3631-3637. https://doi.org/10.1158/1078-0432.CCR-11-0175

[3] Morishita, K., et al. (1992) Activation of EVI1 Gene Expression in Human Acute Myelogenous Leukemias by Translocations Spanning 300-400 Kilobases on Chromosome Band 3q26. Proceedings of the National Academy of Sciences of the United States of America, 89, 3937-3941. https://doi.org/10.1073/pnas.89.9.3937

[4] Morishita, K., Parker, D.S., Mucenski, M.L., Jenkins, N.A., Copeland, N.G. and Ihle, J.N. (1988) Retroviral Activation of a Novel Gene Encoding a Zinc Finger Protein in IL-3-Dependent Myeloid Leukemia Cell Lines. Cell, 54, 831-840. https://doi.org/10.1016/S0092-8674(88)91175-0 
[5] Hoyt, P.R., et al. (1997) The Evil Proto-Oncogene Is Required at Midgestation for Neural, Heart, and Paraxial Mesenchyme Development. Mechanisms of Development, 65, 55-70. https://doi.org/10.1016/S0925-4773(97)00057-9

[6] Goyama, S., et al. (2008) Evi-1 Is a Critical Regulator for Hematopoietic Stem Cells and Transformed Leukemic Cells. Cell Stem Cell, 3, 207-220. https://doi.org/10.1016/j.stem.2008.06.002

[7] Kazama, H., Kodera, T., Shimizu, S., Mizoguchi, H. and Morishita, K. (1999) Ecotropic Viral Integration Site-1 Is Activated During, and Is Sufficient for, Neuroectodermal P19 Cell Differentiation. Cell Growth \& Differentiation, 10, 565-573.

[8] Van Campenhout, C., et al. (2006) Evil Is Specifically Expressed in the Distal Tubule and Duct of the Xenopus Pronephros and Plays a Role in Its Formation. Developmental Biology, 294, 203-219. https://doi.org/10.1016/j.ydbio.2006.02.040

[9] Bard-Chapeau, E.A., et al. (2014) Mice Carrying a Hypomorphic Evil Allele Are Embryonic Viable but Exhibit Severe Congenital Heart Defects. PLoS One, 9, e89397. https://doi.org/10.1371/journal.pone.0089397

[10] Seale, P., et al. (2008) PRDM16 Controls a Brown Fat/Skeletal Muscle Switch. Nature, 454, 961-967. https://doi.org/10.1038/nature07182

[11] Ishibashi, J., et al. (2012) An Evil-C/EBP $\beta$ Complex Controls Peroxisome Proliferator-Activated Receptor $\gamma_{2}$ Gene Expression to Initiate White Fat Cell Differentiation. Molecular and Cellular Biology, 32, 2289-2299. https://doi.org/10.1128/MCB.06529-11

[12] An, Q., Wu, D., Ma, Y., Zhou, B. and Liu, Q. (2015) Suppression of Evil Promotes the Osteogenic Differentiation and Inhibits the Adipogenic Differentiation of Bone Marrow-Derived Mesenchymal Stem Cells in Vitro. International Journal of Molecular Medicine, 36, 1615-1622. https://doi.org/10.3892/ijmm.2015.2385

[13] Morishita, K., Parganas, E., Douglass, E.C. and Ihle, J.N. (1990) Unique Expression of the Human Evi-1 Gene in an Endometrial Carcinoma Cell Line: Sequence of cDNAs and Structure of Alternatively Spliced Transcripts. Oncogene, 5, 963-971.

[14] Alzuherri, H., McGilvray, R., Kilbey, A. and Bartholomew, C. (2006) Conservation and Expression of a Novel Alternatively Spliced Evil Exon. Gene, 384, 154-162. https://doi.org/10.1016/j.gene.2006.07.027

[15] Sood, R., Chakrabarti, S.R. and Nucifora, G. (1999) MDS1/EVI1 Enhances TGF-Bold $\beta 1$ Signaling and Strengthens Its Growth-Inhibitory Effect, but the Leukemia-Associated Fusion Protein AML1/MDS1/EVI1, Product of the T(3;21), Abrogates Growth-Inhibition in Response to TGF-Bold $\beta 1$. Leukemia, 13, 348-357. https://doi.org/10.1038/sj.leu.2401360

[16] Sitailo, S., Sood, R., Barton, K. and Nucifora, G. (1999) Forced Expression of the Leukemia-Associated Gene EVI1 in ES Cells: A Model for Myeloid Leukemia with 3q26 Rearrangements. Leukemia, 13, 1639-3645.

https://doi.org/10.1038/sj.leu.2401585

[17] Fog, C.K., Galli, G.G. and Lund, A.H. (2012) PRDM Proteins: Important Players in Differentiation and Disease. Bioessays, 34, 50-60. https://doi.org/10.1002/bies.201100107

[18] Pinheiro, I., et al. (2012) Prdm3 and Prdm16 Are H3K9me1 Methyltransferases Required for Mammalian Heterochromatin Integrity. Cell, 150, 948-960. https://doi.org/10.1016/j.cell.2012.06.048

[19] Kilbey, A. and Bartholomew, C. (1998) Evi-1 ZF1 DNA Binding Activity and a Second Distinct Transcriptional Repressor Region Are both Required for Optimal 
Transformation of Rat1 Fibroblasts. Oncogene, 16, 2287-2291. https://doi.org/10.1038/sj.onc.1201732

[20] Bartholomew, C., Kilbey, A., Clark, A.M. and Walker, M. (1997) The Evi-1 Proto-Oncogene Encodes a Transcriptional Repressor Activity Associated with Transformation. Oncogene, 14, 569-577. https://doi.org/10.1038/sj.onc.1200864

[21] Livak, K.J. and Schmittgen, T.D. (2001) Analysis of Relative Gene Expression Data Using Real-Time Quantitative PCR and the 2(-Delta Delta C(T)) Method. Methods, 25, 402-408. https://doi.org/10.1006/meth.2001.1262

[22] Wimmer, K., Vinatzer, U., Zwirn, P., Fonatsch, C. and Wieser, R. (1998) Comparative Expression Analysis of the Antagonistic Transcription Factors EVI1 and MDS1-EVI1 in Murine Tissues and during in Vitro Hematopoietic Differentiation. Biochemical and Biophysical Research Communications, 252, 691-696. https://doi.org/10.1006/bbrc.1998.9588

[23] Roy P., et al. (2010) Enhanced Sensitivity to Hydrogen Peroxide-Induced Apoptosis in Evi1 Transformed Rat1 Fibroblasts Due to Repression of Carbonic Anhydrase III. The FEBS Journal, 277, 441-452. https://doi.org/10.1111/j.1742-4658.2009.07496.x

[24] Lynch, C.J., Hazen, S.A., Horetsky, R.L. and Carter, N.D. (1993) Differentiation-Dependent Expression of Carbonic Anhydrase II and III in 3T3 Adipocytes. American Journal of Physiology, 265, 234-243.

[25] Palmer S., et al. (2001) Evi-1 Transforming and Repressor Activities Are Mediated by CtBP Co-Repressor Proteins. Journal of Biological Chemistry, 276, 25834-25840. https://doi.org/10.1074/jbc.M102343200

[26] Student, A.K., Hsu, R.Y. and Lane, M.D. (1980) Induction of Fatty Acid Synthetase Synthesis in Differentiating 3T3-L1 Preadipocytes. Journal of Biological Chemistry, $255,4745-4750$.

[27] Miller, D.G., Adam, M.A. and Miller, A.D. (1990) Gene Transfer by Retrovirus Vectors Occurs only in Cells that Are Actively Replicating at the Time of Infection. Molecular and Cellular Biology, 10, 4239-4242. https://doi.org/10.1128/MCB.10.8.4239

[28] Otto, T.C. and Lane, M.D. (2005) Adipose Development: From Stem Cell to Adipocyte. Critical Reviews in Biochemistry and Molecular Biology, 40, 229-242. https://doi.org/10.1080/10409230591008189

[29] Kilbey, A., Stephens, V. and Bartholomew, C. (1999) Loss of Cell Cycle Control by Deregulation of Cyclin-Dependent Kinase 2 Kinase Activity in Evi-1 Transformed Fibroblasts. Cell Growth \& Differentiation, 10, 601-610.

[30] Morishita, K., Parganas, E., Parham, D.M., Matsugi, T. and Ihle, J.N. (1990) The Evi-1 Zinc Finger Myeloid Transforming Gene Is Normally Expressed in the Kidney and in Developing Oocytes. Oncogene, 5, 1419-1423.

[31] Sayadi, A., et al. (2015) Functional Features of EVI1 and EVI1Delta324 Isoforms of MECOM Gene in Genome-Wide Transcription Regulation and Oncogenicity. Oncogene, 35, 2311-2321.

[32] Izutsu, K., Kurokawa, M., Imai, Y., Maki, K., Mitani, K. and Hirai, H. (2001) The Corepressor CtBP Interacts with Evi-1 to Repress Transforming Growth Factor $\beta$ Signaling. Blood, 97, 2815-2822. https://doi.org/10.1182/blood.V97.9.2815

[33] Sue, N., et al. (2008) Targeted Disruption of the Basic Krüppel-Like Factor Gene (Klf3) Reveals a Role in Adipogenesis. Molecular and Cellular Biology, 28, 39673978. https://doi.org/10.1128/MCB.01942-07

[34] Jack, B.H.A. and Crossley, M. (2010) GATA Proteins Work Together with Friend of 
GATA (FOG) and C-Terminal Binding Protein (CTBP) Co-Regulators to Control Adipogenesis. Journal of Biological Chemistry, 285, 32405-32414. https://doi.org/10.1074/jbc.M110.141317

[35] Kajimura, S., et al. (2008) Regulation of the Brown and White Fat Gene Programs through a PRDM16/CtBP Transcriptional Complex. Genes \& Development, 22, 1397-1409. https://doi.org/10.1101/gad.1666108

[36] Zhang, Q., Piston, D.W. and Goodman, R.H. (2002) Regulation of Corepressor Function by Nuclear NADH. Science, 295, 1895-1897.

[37] Jack, B.H.A., Pearson, R.C. and Crossley, M. (2011) C-Terminal Binding Protein: A Metabolic Sensor Implicated in Regulating Adipogenesis. The International Journal of Biochemistry \& Cell Biology, 43, 693-696.

https://doi.org/10.1016/j.biocel.2011.01.017

Submit or recommend next manuscript to SCIRP and we will provide best service for you:

Accepting pre-submission inquiries through Email, Facebook, LinkedIn, Twitter, etc. A wide selection of journals (inclusive of 9 subjects, more than 200 journals) Providing 24-hour high-quality service User-friendly online submission system Fair and swift peer-review system Efficient typesetting and proofreading procedure Display of the result of downloads and visits, as well as the number of cited articles Maximum dissemination of your research work

Submit your manuscript at: http://papersubmission.scirp.org/

Or contactym@scirp.org 